\title{
UM MODELO PARA FORMULAÇÃO DE PERGUNTAS GEOESPACIAIS EM SIG, BASEADO NA MATRIZ GEOGRÁFICA DE BERRY (1964)
}

\author{
Marcos César Ferreira ${ }^{1}$ \\ "O espaço é aquilo que impede que tudo esteja no mesmo lugar". \\ Paul Virilio, 1993.
}

Resumo: Tem-se notado desde o início deste século, significativo aumento no número de geógrafos a utilizar ferramentas de geoprocessamento em suas pesquisas. Este fenômeno tem sido influenciado também pela recente simplificação e difusão das formas de interação com computadores, baseadas, principalmente, na sofisticação visual dos aplicativos de uso pessoal. Este contexto tem motivado novos geógrafos a utilizar o SIG como ferramenta técnica instantânea de manipulação de mapas e dados espaciais, e não como uma fase intermediária de procedimento metodológico de análise do espaço geográfico. Neste sentido, a proposta deste artigo é apresentar um modelo teórico-metodológico para uso dos SIG, baseado em uma tipologia de perguntas geoespaciais construídas segundo os paradigmas de sítio e situação, e estruturadas visualmente segundo a clássica matriz geográfica de Berry (1964). A cada pergunta apresentamos um procedimento para sua solução baseado nos módulos de análise espacial do sistema de informação geográfica Idrisi Andes.

Palavras-chave: SIG; análise espacial; geografia; matriz geográfica; perguntas geoespaciais; geoprocessamento; Berry.

\section{A model for geoespatial questions formulation in GIS environment, based on Berry (1964) geographical matrix}

\begin{abstract}
A significant increase in the number of geographers using GIS tools in their research has been noted since the beginning of this century. This phenomenon has also been influenced by the recent simplification and diffusion of forms of interaction with computers, mainly those based on the visual sophistication of applications for personal use. This context has motivated new geographers to use GIS as a technical tool for quickly manipulation of maps and spatial data, and not as an intermediate stage of methodological procedure of geographic space analysis. In this sense, the purpose of this article is to present a theoretical and methodological framework for the use of GIS, based on a typology of spatial questions constructed according to the paradigms of site and situation, and visually structured according to the classical geographical matrix of Berry (1964). To each spatial question, we present a solution based on spatial analysis module of Idrisi Andes GIS.
\end{abstract}

Key Words - GIS; spatial analysis; Geography; geospatial questions; spatial knowledge; geoprocessing; geographical matrix; Berry.

\footnotetext{
${ }^{1}$ Bacharel em Geografia pela UNESP (1987), Mestre em Sensoriamento Remoto pelo INPE (1991), Doutor em Geografia Física pela USP (1995) e Livre-Docente pela UNICAMP (2004). Atualmente é Professor Associado do Instituto de Geociências da UNICAMP. DOI: 10.7154/RDG.2013.0026.0013
} 


\section{INTRODUÇÃO}

A difusão das tecnologias de informação geográfica observada a partir do início deste século tem ampliado continuamente o número de usuários de softwares de geoprocessamento em todo o mundo. A facilidade de interação homem-computador, proporcionada pela agilidade e a acessibilidade a novas interfaces e hardwares, deu à geoinformática importância de um novo paradigma. Tal situação de excesso tem levado novas gerações de geógrafos que praticam o geoprocessamento a acreditarem, ingenuamente, que o sistema de informação geográfica (SIG) é um método de investigação espacial completo.

No campo das tecnologias de informação geográfica é possível se constatar esta "totemização" computacional, natural em um momento histórico em que somos forçados a acreditar que as telas são as melhores (e únicas) maneiras de nos comunicarmos com o mundo. Virilio (1993) já alertava no final do século XX para a entrada da sociedade em uma fase de interfaces de telas. Referindo-se ao contexto do espaço arquitetônico, Virilio ressaltou as mudanças nos conceitos de posição e distância - herdados da "topologia eletrônica" produzida pelas interfachadas de monitores e telas:

“(...) privado de limites objetivos, o elemento arquitetônico passa a estar à deriva, a flutuar em um éter eletrônico desprovido de dimensões espaciais, mas inscrito em uma temporalidade única de uma difusão instantânea (p. 910) (...). O desequilíbrio entre a informação direta de nossos sentidos e a informação mediatizada das tecnologias avançadas é hoje tão grande que terminamos por transferir nossos julgamentos de valor, nossas medidas das coisas, do objeto para a figura, da forma para a imagem, assim como, dos episódios da nossa história para a tendência estatística - de onde, o grande risco tecnológico de um delírio generalizado de interpretação (p. 40)".

Destacamos este pensamento de Virilio, não como palavras de ordem por uma contrarreforma antidigital e extemporânea, em busca de tempo perdido, ou como uma volta à era dos telégrafos, dos dirigíveis, do telex ou da régua de cálculo. Pretendemos, sim, lembrar os novos geógrafos formados junto com SIG, da necessidade de adotarmos uma postura mais crítica com relação às tecnologias de informação geográfica. Entendemos como crítica a postura que considera a existência de uma ciência da informação geográfica, que foi edificada muito antes dos computadores e sem o auxílio deles, e sugeriu paradigmas importantes para o planejamento das ações de análise espacial realizadas hoje, nos SIG, por meio de suas telas e interfachadas. 
Temos notado na geografia, e com satisfação, o crescimento do número de alunos que fazem uso dos SIG nas mais diversas disciplinas geográficas. Além disto, o SIG tem permitido a outros profissionais saber do que a geografia é capaz e facilitado o trânsito entre ela e outras ciências que têm o espaço também como seu objeto de estudo, como a Arquitetura, a Ecologia, a Biologia, a Demografia, entre outras. O que nos preocupa, entretanto, é o fato de alguns dos novos alunos dos cursos de graduação em geografia - inevitáveis atores e usuários de tecnologias de informação geográfica, como quase todos os de sua geração acreditarem que o SIG é apenas um aglomerado de técnicas sem uma ciência que lhe dê sustentação; ou ainda, que só é possível pensar em análise espacial se o SIG já foi carregado para a tela; e, mais além, que a geografia não contribuiu com alguns de seus paradigmas, para a análise geoespacial processada dentro do SIG.

\section{A Escola Locacional da Geografia}

Sabemos que a geografia nunca ocupou posição confortável dentro do conhecimento científico formal. Esta dificuldade de posicionamento epistemológico se deve, sobretudo, a dois fatores fundamentais destacados há muito tempo por Haggett (1969): a ambivalência natural segundo a qual o geógrafo vê seu objeto de estudo e, a que segmento da realidade o geógrafo deve se dedicar em suas pesquisas e estudos. Pelos ensinamentos das disciplinas de história de pensamento geográfico e metodologia em geografia, sabemos que esta ambiguidade foi responsável pela existência plural de pelo menos quatro escolas clássicas na geografia: diferenciação areal, paisagística, ecológica e locacional.

Sack (1974) sustentou a ideia de que a escola geográfica da diferenciação areal - a mais tradicional da geografia - teria o sinônimo de escola corológica (chorus = lugar, espaço). Este geógrafo ressaltou que a abordagem corológica contempla "descrições das características de uma região específica (...) sintetizadas a partir de seus componentes e suas relações (...) por meio da combinação entre fenômenos inter-relacionados" (SACK, 1974b, p.441). Esta afirmativa é base para as tradicionais abordagens geográficas baseadas nos estudos de caso - o bairro, a bacia hidrográfica, a região.

Segundo os pressupostos desta escola, o conhecimento da Terra se daria por meio do método geográfico de diferenciação e integração areal, que se apoia na ideia da desigualdade na distribuição dos objetos sobre a Terra. Surgiram nesta escola os conceitos de lugar, região e área específica. Esta abordagem pode ter origem ensinamento formal 
grego baseado na "curiosidade básica do homem em conhecer o que existe além da colina" (HAGGETT, 1969, p. 10), que possibilitou a conclusão empírica sobre as diferenças aparentes existentes no espaço terrestre. As demais escolas geográficas - paisagem, ecológica e locacional - seriam derivadas da escola corológica (HAGGETT, 1969).

A escola da paisagem, fortemente influenciada por geógrafos germânicos, ofereceu uma visão alternativa à escola da diferenciação espacial. Dolfuss (1973) definiu paisagem como o aspecto visível e diretamente perceptível do espaço. Christofoletti $(1976$, p.11) a via como um conjunto de "elementos geográficos que se articulam uns em relação aos outros; (...) e podem pertencer ao domínio natural, humano, social ou econômico". Desdobraram-se desta escola os conceitos de paisagem natural (original e pré-existente à ocupação antrópica) e paisagem cultural (transformada pela ação humana). A abordagem da paisagem se aproxima da teoria geral dos sistemas, quando aborda o espaço como conjunto de elementos que se articulam e trocam entre si matéria e energia, em um sistema composto por unidades espaciais hierárquicas, tais como geossistema (regional), geofácie e geótopo (local). Esta abordagem sistêmica da paisagem foi praticada com grande destaque por geógrafos do leste europeu (Sotchava) e franceses (Bertrand), por exemplo.

A escola ecológica entende a geografia como relação entre o homem e a Terra, ou relação entre a sociedade humana e o ambiente físico. Encontrou inicialmente grande eco na antiga geografia francesa, principalmente nas pesquisas de Vidal de la Blache (influências do ambiente no homem e o determinismo ambiental); Max Sorre (o homem é parte do meio influências na epidemiologia) e, Jean Brunhes (a ocupação humana da superfície terrestre é fato ambiental essencial). A partir da visão de Brunhes, a escola ecológica, de certo modo, contribuiu para a formação do pensamento ambientalista contemporâneo.

Para a escola locacional - que edificou, a nosso ver, a base teórica e os paradigmas compatíveis com o SIG e a análise espacial - a geografia seria também uma ciência da localização e da distribuição espacial dos fenômenos. Esta abordagem espacial teve forte influência da geometria e da topologia do espaço (HAGGETT, 1969). Por isto, para esta escola, a posição relativa dos objetos é um argumento empírico fundamental, pois ele fundamenta tanto as sintaxes das perguntas geoespaciais, como interpreta, e importa da estatística, a noção de variável espacial. Sack (1974a) deixou claro que a geometria é uma das bases da escola locacional, e, portanto, o espaço pode ser considerado também como distribuição relativa de objetos em padrões e arranjos espaciais (FERREIRA, 2006). 
Coffey (1981) argumentou que a geometria teve influência relevante nesta escola, pois as propriedades geométricas estão ocultas em um dos principais paradigmas da escola locacional que trata do arranjo espacial dos fenômenos geográficos: a dependência espacial. Hepple (1973) mostrou, de forma radical, a relação existente entre os conceitos de dependência espacial e organização espacial, ao afirmar que, se um valor para um dado ponto do espaço não tiver relação como outros valores situados em sua vizinhança, então não haverá ou organização espacial a ser explicada.

As chamadas "disciplinas técnicas" - como são conhecidos sensoriamento remoto, cartografia, análise espacial e geoprocessamento - estão incluídas na grade curricular da maioria dos cursos de graduação em geografia, em parte, por influência dos pressupostos da escola locacional. A generalização espacial dos fenômenos geográficos, e a formulação de hipóteses acerca dos fatores que contribuem para que alguns destes fenômenos tenham organização espacial diferente de outros, fazem parte do método locacional.

Entre os paradigmas mais importantes da escola locacional, e que influenciaram indiretamente o desenho do SIG nos anos 1960, estão sítio e situação. Estes paradigmas foram estabelecidos pelo geógrafo americano Brian Berry, em 1964. Para Berry, o sítio é um conceito vertical e associativo entre atributos corológicos, algo similar à área geográfica específica; esta associação vertical particular e específica entre atributos temáticos dá unicidade e especificidade a um lugar. Ainda conforme nos mostrou Berry, um sítio pode ser comparado a outros sítios, com base na abordagem da diferenciação areal. O sítio é então, a substância do lugar (SACK,1974).

Se o sítio é a substância, qual será então a instância deste lugar? A instância é a distribuição espacial ou a situação. A situação é horizontal (mapa) e permite a representação da "interdependência regional, das conexões entre lugares e da interação espacial" (BERRY, 1964); a situação é, portanto, um conceito geométrico estabelecido por relações horizontais de vizinhança, distância e contiguidade - relações básicas de toda a análise espacial de fenômenos geográficos realizada em SIG. Para complementação desta discussão sobre as bases teórico-metodológicas do SIG na geografia, consulte o texto integral em Ferreira (2006) - de onde alguns dos trechos acima foram emprestados. 


\section{A Matriz Geográfica}

Berry (1964) integrou os conceitos de sítio e situação em uma estrutura matricial - ao que denominou matriz geográfica - onde, em cada intersecção entre linhas e coluna localiza-se um fato geográfico (Figura 1). Esta estrutura de consulta espacial de dupla entrada combina duas séries geográficas: a série de valores de várias características que ocorrem em apenas um lugar (sítio); e a série de valores de apenas uma característica, que ocorre em todos os lugares (situação). Nesta matriz o termo característica tem significado similar aos de atributo, variável espacial ou tema.

Observe na Figura 1 a estrutura tridimensional da matriz geográfica, definida pelo eixo vertical da série de lugares ou posições no espaço $\left(L_{1} \ldots L_{n}\right)$; pelo eixo horizontal da série das características ou variáveis $\left(C_{1} \ldots C_{n}\right)$ e pelo eixo de profundidade da série das posições no tempo $\left(T_{1} \ldots T_{n}\right)$. A Figura 2 representa, graficamente, as abordagens sítio e situação baseadas na matriz geográfica. Observe que cada uma destas abordagens se relaciona a um entre dois tipos de consulta espacial: inventário locacional (sítio) e distribuição espacial (o mapa, ou a situação).

No inventário locacional, a pergunta geoespacial mais adequada seria "O que existe aqui?" ou, a uma busca pelo lugar, cujos resultados mostram os valores de todas as variáveis, manifestados neste lugar ou nesta posição do espaço (Figura 2a). Na distribuição espacial, a pergunta geoespacial é distributiva ou "mapeável", e pode ser assim formulada: "Qual é o valor desta característica em vários lugares onde ela foi observada?" O resultado é o mapa temático ou a superfície que representam a variabilidade espacial desta característica consultada (Figura 2b). Entretanto, estas duas formas de consulta espacial consideram que o tempo é constante, isto é, tanto o lugar como a característica não sofrem influência da passagem do tempo. Contudo, uma abordagem geográfica completa deveria incluir a periodicidade temporal dos eventos, já que, em geografia, tempo e espaço são conceitos interdependentes.

Com base em sua matriz geográfica, Berry propôs dez tipos de abordagem espacial, combinado as três séries: tempos, lugares e características. Sete destas abordagens podem ser transformadas em perguntas geoespaciais, solucionadas por meio do uso de operações entre mapas realizadas em SIG. Estas perguntas podem fornecer orientação metodológica às etapas de consulta e modelagem espacial em SIG, materializada a partir do uso de sequências de comandos ou funções disponíveis nos SIG. 
As duas abordagens mostradas na Figura 2 constituem-se, de fato, em metodologias gerais de análise espacial geográfica - sejam elas realizadas em SIG-software (com apoio de computadores), ou em SIG analógico ou manual (sem o apoio de computadores). Estas formas de abordar um problema de investigação geográfica baseado em mapas dependem de como elaboramos perguntas geoespaciais. Não nos basta ter em mãos (ou no hardware) mapas, tabelas, imagens e SIG; é necessária também a capacidade de formularmos perguntas geoespaciais que impulsionem a análise espacial e nos devolvam como respostas, outros mapas, outras imagens, outras tabelas - e outras perguntas e dúvidas!

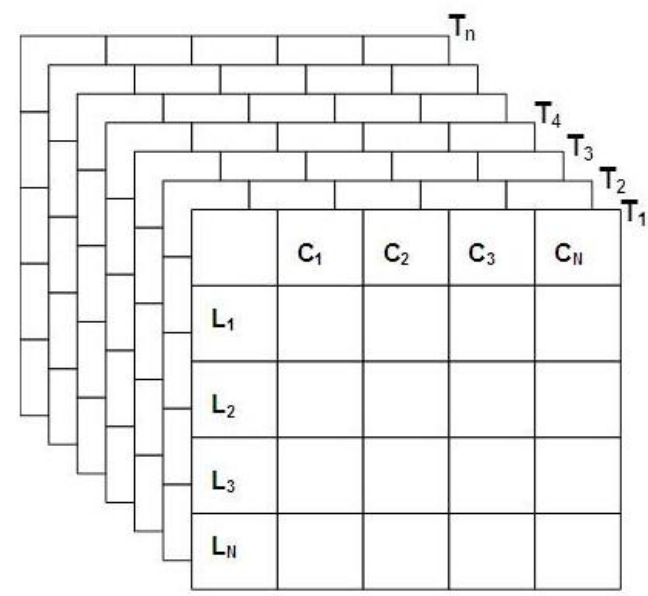

Figura 1 - Matriz geográfica proposta por Berry (1964). As colunas correspondem a séries de características; as

linhas correspondem a séries de lugares ou posições no plano. Os múltiplos planos em profundidade representam recortes no tempo, ou periodização histórica do fato geográfico. (Fonte: adaptado e modificado de Berry, 1964).

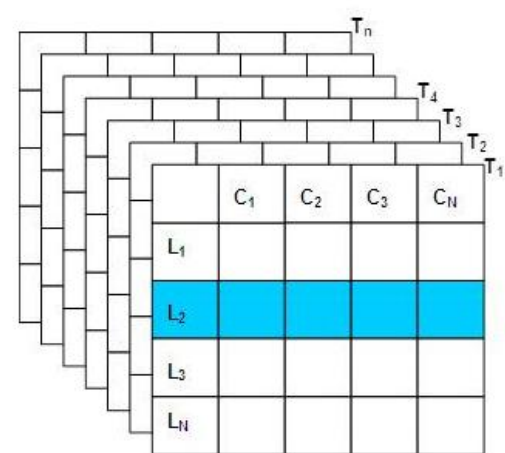

Sítio (A)

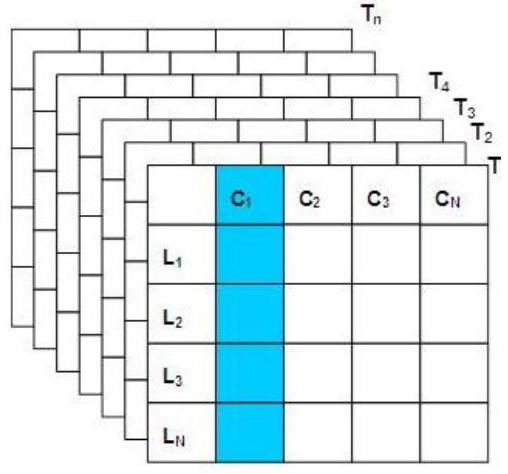

SITUAÇÃO (B)

Figura 2 - Modelos gráficos derivados da matriz geográfica, representando as abordagens baseadas nos sítios

(A) - várias características em um só lugar, e, na situação (B), uma característica em vários lugares.

A partir da Figura 2 podemos elaborar várias perguntas geoespaciais - sejam elas monotemporais ou multitemporais - cuja estrutura baseia-se na matriz geográfica e a solução pode ser obtida por meio do uso raciocinado de módulos ou comandos de um SIG. 
Gostaríamos de deixar claro ao iniciante em geoprocessamento, que o processamento mental dos dados geográficos, na forma das perguntas geoespaciais e abordagens baseadas em sítio e situação, são tão importantes como o SIG e os dados espaciais nele processados. A formulação destas perguntas geoespaciais parece ser relativamente simples. Mas, quando transformadas em uma sequência de comandos de SIG, assumem complexidade inesperada. Objetivamente falando, o SIG deve ser utilizado para dar respostas a estas perguntas - sejam elas na forma de novos mapas, tabelas ou textos - e não apenas como anseio de modernidade ou maior eficiência analítica comparada aos tempos pretéritos.

Berry (1964) já havia postulado algumas abordagens derivadas desta matriz, mas não as havia ainda associado a perguntas geoespaciais. A seguir, apresentamos um novo modelo que combina a estrutura da matriz geográfica a perguntas geoespaciais possíveis de serem formuladas em atividades cotidianas de análise espacial em SIG.

\section{O Modelo Proposto}

O modelo de abordagem teórico-metodológico aqui proposto baseia-se em sete tipos de perguntas geoespaciais, que podem ser formuladas a um SIG, e cujas características dependem da forma como elas integram, na matriz geográfica, os conceitos de sítio, situação e tempo. Os exemplos de perguntas geoespaciais aqui apresentados são baseados em um contexto genérico de pesquisas na área ambiental, e têm como propósito principal, mostrar como elas são construídas a partir de uma sintaxe combinando a tríade sítiosituação-tempo. Além do modelo gráfico da matriz geográfica, apresentamos também um sequenciamento de soluções para estas perguntas, adotando-se como exemplo algumas ferramentas de análise espacial SIG Idrisi Andes (EASTMAN, 2010). Estas soluções podem ser adaptadas a sistemas como QuantumGIS e ArcGIS, entre outros.

Tipo I - Perguntas geoespaciais simples, por local e no tempo $t_{i}$

$\checkmark$ Qual é a área total de fragmentos florestais $\left(\boldsymbol{C}_{1}\right)$, culturas de soja $\left(\boldsymbol{C}_{2}\right)$ e silvicultura ( $\left.C_{3}\right)$ no município $L_{i}$, em $2013\left(T_{i}\right)$ ? 
(Sítio)

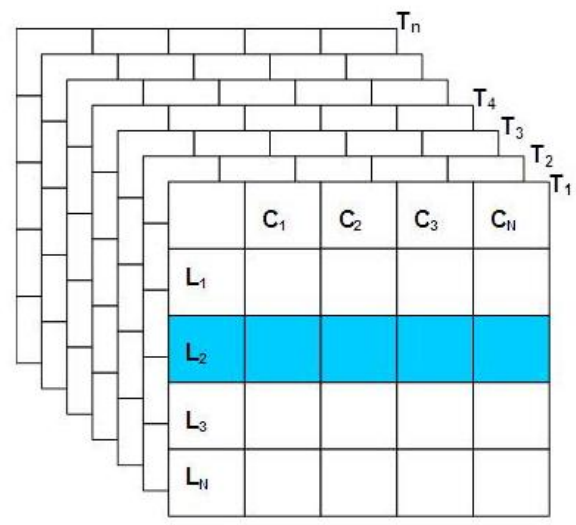

Figura 3 - Pergunta geoespacial simples, por local $L_{1}$ e no tempo $T_{1}$.

Esta pergunta geoespacial tem solução muito simples em qualquer SIG. Por exemplo, no Idrisi, depois do mapa ser carregado para a tela utiliza-se a ferramenta de consulta simples denominada Area, disponível no módulo GIS Analysis/Database Query, que extrai as áreas das classes do mapa, apresentando-as como uma tabela ou como um mapa quantitativo das áreas destas classes. Neste último caso, as classes do mapa podem ser simbolizadas pela variável visual valor, que associará ao tamanho da área de cada classe do mapa, um grau de tonalidade de cor ou tom de cinza.

Tipo II - Perguntas geoespaciais sobre distribuições geográficas de uma só característica, em um tempo $t_{i}$

$\checkmark$ Onde ocorrem fragmentos florestais $\left(\boldsymbol{C}_{1}\right)$ na região formada pelo conjunto de municípios $L_{1} L_{2}, L_{3} \ldots L_{n}$ em $2013\left(T_{1}\right)$ ?

Este tipo de pergunta considera que a característica $C_{1}$ é um mapa binário representando somente áreas ocupadas pela classe fragmentos florestais. A resposta a esta pergunta no SIG se inicia pela transformação do mapa de uso do solo em um mapa binário. No módulo GIS Analysis encontramos a função Reclass, situada no Database Query. 


\section{(Situação)}

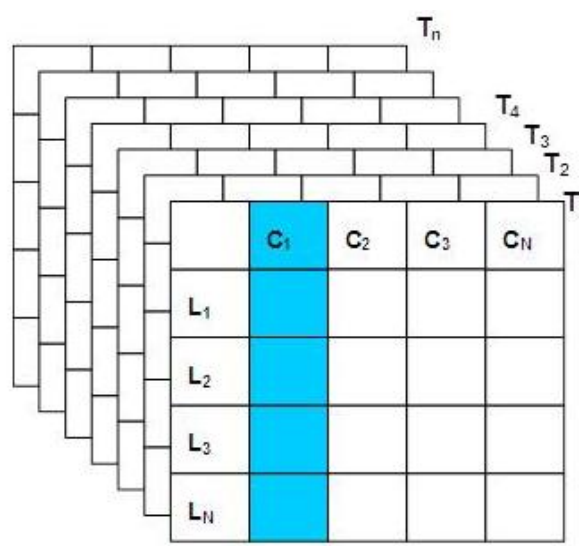

Figura 4 - Pergunta geoespacial sobre distribuições geográficas de uma só característica, em um Tempo $T_{i}$

A reclassificação atribui código 1 para as áreas de fragmentos florestais e 0 para as demais classes. $O$ mapa da característica $C_{1}$ é então sobreposto ao mapa dos municípios $L_{1}, L_{2}, L_{3} \ldots L_{n}$, solucionando-se assim a pergunta geoespacial formulada acima.

Estamos diante de uma abordagem espaço-tempo simples, que requer uma base de dados com seis mapas de uso do solo (1960, 1970,1980, 1990, 2000 e 2010) para um mesmo local $\left(L_{2}\right)$. A resposta se inicia acessando-se o módulo GIS Analysis e, em seguida, o Changes/Time Series, que contém várias funções de análise espaço-tempo baseadas em mapas temáticos e superfícies. Sugerimos como estratégia para responder a tal pergunta o uso da função Imagediff, que realiza uma análise de diferenciação entre pares de mapas temáticos situados em posições de tempo $T_{n}$ e $T_{n+1}$, por meio de máscaras booleanas.

Como resultados desta análise, são produzidos pelo menos três tipos de mapas: diferenças espaciais entre classes, porcentagem de mudança entre classes e anomalias destas mudanças padronizadas na escala Z. Comparada à pergunta geoespacial anterior, esta apresenta complexidade maior, pois remete a uma abordagem cartográfica dinâmica, que permite a análise de difusão espacial de uma mesma característica $\left(C_{2}\right)$.

Tipo III - Perguntas geoespaciais sobre a evolução temporal de um local, com base em várias características manifestadas neste local

$\checkmark$ Como evoluíram, década a década, as áreas de cana de açúcar $\left(\boldsymbol{C}_{1}\right)$, cerrado $\left(\boldsymbol{C}_{2}\right)$, matas $\left(\boldsymbol{C}_{3}\right)$ e pastagem $\left(\boldsymbol{C}_{4}\right)$, no município $\left(\boldsymbol{L}_{1}\right)$, entre $1960\left(\boldsymbol{T}_{1}\right)$ e $2010\left(\boldsymbol{T}_{50}\right)$ ? 


\section{(Sítio no Tempo)}

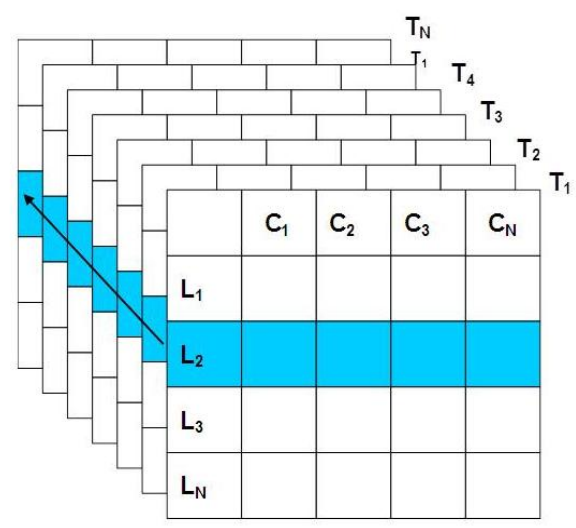

Figura 5 - Pergunta geoespacial sobre a evolução temporal de um local, com base em várias características manifestadas neste local.

Tipo IV - Perguntas geoespaciais sobre a evolução espaço-tempo de uma única característica, ou sobre processos de difusão espacial de uma característica.

$\checkmark$ Como evoluiu, década a década, a distribuição espacial das áreas de cerrado $\left(\boldsymbol{C}_{2}\right)$ na região sudeste de Goiás $\left(\boldsymbol{L}_{1}, \boldsymbol{L}_{2}, \boldsymbol{L}_{3} \ldots \boldsymbol{L}_{N}\right)$ entre $1960\left(\boldsymbol{T}_{1}\right)$ e $2010\left(\boldsymbol{T}_{5}\right)$ ?

\section{(Situação no tempo)}

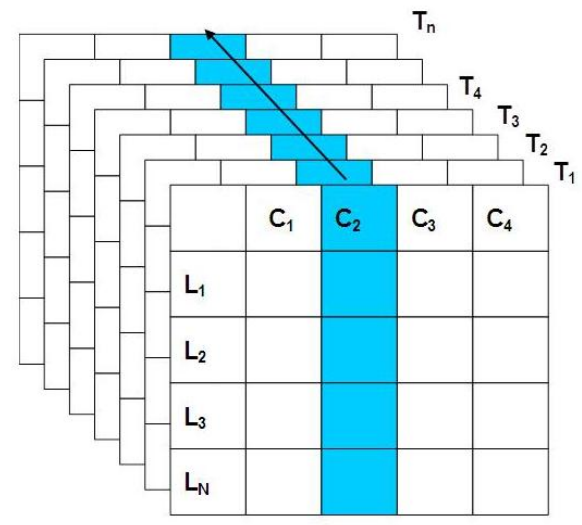

Figura 6 - Perguntas geoespaciais sobre a evolução espaço-tempo de uma única característica, ou sobre processos de difusão de uma característica.

Neste caso, a pergunta quer como resposta os padrões espaciais de expansão e contração areal de uma característica, produzidos com a passagem do tempo. No módulo GIS Analysis > Changes/Time Series podemos utilizar a ferramenta Media Viewer, que possibilita a visualização cinemática dos mapas a partir de arquivos de vídeo no formato AVI, em uma sequencia dos mapas apresentados em intervalos de tempo pré-definidos. Esta estratégia é 
muito interessante, pois nos dá a compreensão dos movimentos isotrópicos e anisotrópicos das áreas gerados pela passagem do tempo. Além disto, nos dá indicação das direções em que a mobilidade das áreas foi mais veloz (hipóteses sobre porosidade espacial e corredores); e das direções onde a mobilidade foi mais lenta (hipóteses sobre barreiras espaciais ou impedâncias).

Outra solução para esta pergunta geoespacial, relativamente mais complexa, pode ser obtida por meio do uso de modelagem baseada em autômatos celulares. Dentro do módulo GIS Analysis > Changes/Time Series, encontramos a função Cellatom. Esta função de modelagem dinâmica simula o estado futuro de um pixel do mapa, em função do seu estado atual e do estado dos pixels vizinhos. Podemos utilizar também como referência para os estados futuros de um pixel, evidências encontradas na evolução da característica $C_{n}$ em anos anteriores (ver acima, como exemplo, a solução apresentada para a pergunta geoespacial do tipo III).

Esta simulação dinâmica pode utilizar também como referência, uma grade de probabilidades do evento expandir-se para um determinado pixel vizinho, considerando-se valores das variáveis que ali se manifestem e exerçam influência positiva na dispersão deste fenômeno.

Tipo V - Perguntas geoespaciais sobre a correspondência entre duas ou mais características que se manifestam em um conjunto de locais

$\checkmark$ Qual é o grau de correspondência espacial entre áreas com ocorrência de voçorocas $\left(\boldsymbol{C}_{1}\right)$ e áreas de latossolos areno-argilosos $\left(\boldsymbol{C}_{2}\right)$ no ano de $2012\left(\boldsymbol{T}_{1}\right)$ ?

A correspondência espacial ou a coincidência espacial entre dois mapas temáticos é utilizada para se estimar a dependência entre duas variáveis geográficas; portanto, a resposta a esta pergunta geoespacial surge das operações clássicas de sobreposição de mapas (overlay), comum em todos os SIG. No caso do Idrisi, podemos solucionar esta pergunta de duas formas: visual e analítico-quantitativa; as duas respostas podem ser obtidas pela função Crosstab, acessada no módulo GIS Analysis/Database Query. 


\section{(Associações entre Situações)}

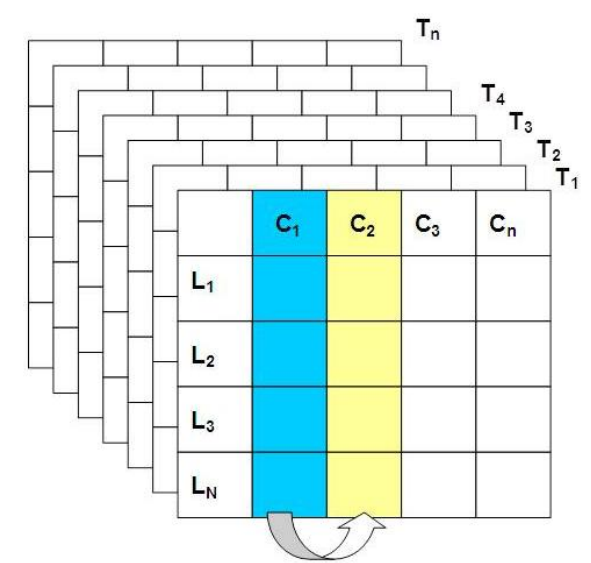

Figura 7 - Pergunta geoespacial sobre a correspondência entre duas ou mais características que se manifestam em um conjunto de locais.

Se escolhermos a forma visual - isto é, obtendo-se como resposta, o mapa da sobreposição das características $\mathrm{C}_{1}$ e $\mathrm{C}_{2}$ - selecionamos a opção cross-classification image. Esta opção utiliza o operador booleano OR para produzir um mapa que soma as legendas dos mapas $C_{1}$ e $C_{2}$. No mapa resultante é possível visualizarmos onde e como as categorias se sobrepõem. Contudo, se optarmos pela análise quantitativa, selecionamos full cross-tabulation table, que gera uma tabela mostrando, nas colunas, as classes do mapa $C_{1} e$, nas linhas, as classes do mapa $C_{2}$. As células desta matriz mostrarão a proporção de coincidência espacial entre as áreas das duas classes.

O grau de associação entre os mapas pode ser estimado tanto pelo índice de agregação de Kappa como pelo índice $\mathrm{V}$ de Cramer - ambos calculados e apresentados junto à tabulação cruzada. Se os mapas $C_{1}$ e $C_{2}$ forem superfícies isopléticas estruturadas em campos contínuos - como isotermas ou isohipsas, dentre outras, por exemplo - a resposta à pergunta geoespacial deve se iniciar pela análise de regressão entre estas superfícies, pelo método de Pearson ou pelo método de Spearman. Nestes casos, as duas superfícies são consideradas populações amostrais de duas variáveis, formadas por $\mathrm{N}$ pixels cada.

Tipo VI - Perguntas geoespaciais baseadas na análise associativa entre dois ou mais locais, a partir de um conjunto de características comuns a eles

$\checkmark$ Dentre o conjunto de todos os municípios do Vale do Ribeira $\left(L_{1}, L_{2}, L_{3} \ldots L_{N}\right)$, quais são os que apresentam mais semelhança segundo a taxa de urbanização $\left(\boldsymbol{C}_{1}\right)$, o PIB per 
capita $\left(\boldsymbol{C}_{2}\right)$, a taxa de mortalidade infantil? $\left(\boldsymbol{C}_{3}\right)$ a taxa de desemprego $\left(\boldsymbol{C}_{3}\right)$, em 2013 $\left(T_{1}\right)$ ?

\section{(Associações entre Sítios)}

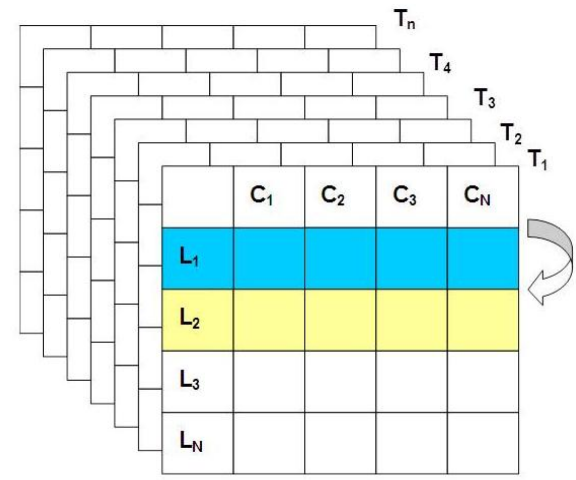

Figura 8 - Perguntas geoespaciais baseadas na análise associativa entre dois ou mais locais, a partir de um conjunto de características comuns a eles.

Esta pergunta pode ser respondida de forma simples e utilizando-se softwares de estatística que contenham aplicativos para análise de agrupamentos e análise fatorial. $\mathrm{O}$ processamento é realizado diretamente na tabela de atributos $C_{1} \ldots C_{n}$ medidos nas localidades $L_{1} \ldots L_{N}$. $O$ resultado da formação dos grupos pode ser representado posteriormente em mapa temático cujas classes correspondam a grupos de localidades mais similares de acordo com um algoritmo de classificação (distância euclidiana, entre outros, por exemplo) e as características $\mathrm{C}_{1} \ldots \mathrm{C}_{\mathrm{n}}$.

Este mesmo tipo de pergunta geoespacial pode ser expandido para modelos de alocação espacial, que atribuem áreas (polígonos ou pixels) a conjuntos (grupos) de suscetibilidade, risco, probabilidade ou adequabilidade a um determinado objetivo ou evento. A regra de decisão para a atribuição pode basear-se na lógica fuzzy e na lógica booleana.

Tipo VII - Perguntas geoespaciais sobre a evolução temporal da dependência espacial entre duas ou mais características, em um conjunto de locais.

$\checkmark$ No período de $1950\left(\boldsymbol{T}_{1}\right)$ a $2010\left(\boldsymbol{T}_{60}\right)$, como evoluiu a correspondência espacial entre o preço do metro quadrado do lote urbano $\left(\boldsymbol{C}_{\mathbf{2}}\right)$ e a distância às áreas verdes $\left(\boldsymbol{C}_{\mathbf{2}}\right)$ em bairros $\left(L_{1}, L_{2}, L_{3} \ldots L_{N}\right)$ da cidade de São Paulo? 


\section{(Evolução temporal de associações entre Situações)}

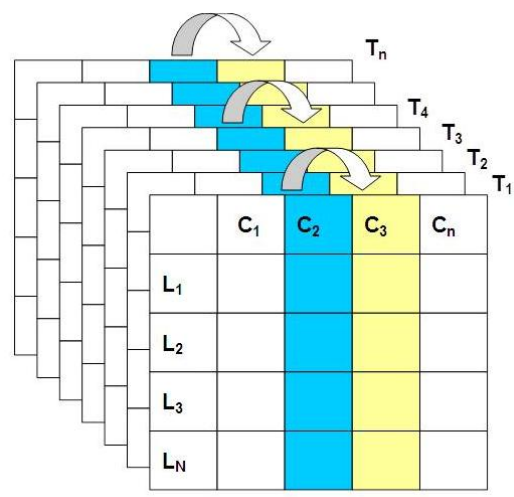

Figura 9 - Perguntas geoespaciais sobre a evolução temporal da dependência espacial entre duas ou mais características, em um conjunto de locais.

A solução a esta pergunta geoespacial pode ser apresentada em formato de um gráfico (curva) da evolução do valor do índice $V$ de Cramer durante o período $T_{1}$ a $T_{n}$ - calculado a partir da mesma estratégia utilizada para responder a pergunta geoespacial do tipo V. Para cada ano é calculado o índice $V$ entre o mapa do preço médio do metro quadrado por bairro e o mapa das isodistâncias até uma área verde mais próxima. Com o passar do tempo, os valores de $\mathrm{V}$ tenderiam a diminuir, já que, mais recentemente, a menor distância a uma área verde tenderia a contribuir positivamente com o preço do solo urbano em algumas metrópoles brasileiras.

A estrutura de todas as perguntas geoespaciais discutidas acima pode ser modificada com relação às dimensões do locacionais consideradas, alterando-se de zonas totais para zonas parciais. Entendemos por zonas totais o espaço formado pelo conjunto de unidades espaciais que formam a totalidade, delimitado por fronteiras reais. As fronteiras das zonas totais corresponderiam aos limites cartográficos reais das diversas categorias de sítios: municípios, regiões, bacias hidrográficas, regiões, entre outras.

Por zonais parciais entendemos as porções incompletas do espaço, delimitadas arbitrariamente por distâncias ou faixas medidas a partir de objetos geográficos reais, como nós, postos, rios, estradas ou áreas, entre outros. São exemplos de zonas parciais os buffers traçados em torno destes objetos geográficos. Tanto as zonas parciais como as zonas totais podem ser consideradas séries de locais $L_{1}, L_{2}, L_{3} \ldots L_{N}$ na matriz geográfica. Mantém-se, no caso das zonas parciais, a mesma representação gráfica das matrizes das figuras 3 a 9 mesmo que elas não formem uma totalidade geográfica. 


\section{CONSIDERAÇÕES FINAIS}

Este texto teve como finalidade motivar a comunidade geográfica acadêmica, iniciante no geoprocessamento, para a continuada reflexão metodológica sobre o uso dos SIG. Sugerimos que ela seja feita segundo os paradigmas da escola locacional da geografia.

Observamos ao longo de quase vinte e cinco anos dedicados ao ensino, orientação acadêmica e pesquisa em análise geoespacial, que a maioria dos iniciantes nesta categoria de investigação não dedica maior atenção às bases teórico-metodológicas da pesquisa realizada por meio de um SIG. Além disto, a maioria deles talvez ainda desconheça os principais paradigmas que contribuíram para criação das funções de análise espacial, mimetizadas como "comandos" de um SIG.

Apresentamos neste breve artigo um modelo teórico de abordagem para SIG, baseado na combinação dos paradigmas da matriz geográfica, concebido por Berry (1964), sítio e situação, difundidos dez anos mais tarde por Sack (1974) e, em um rol de perguntas geoespaciais que podem ser construídas a partir da combinação entre estes paradigmas. Definidos o objetivo da pesquisa, a extensão e a escala do objeto de estudo, passa-se à fase do SIG mental, quando as perguntas geoespaciais e abordagens propostas pelo modelo, podem ser aplicados. Cada tipo de pergunta geoespacial orienta o pesquisador na seleção de conjunto específico de comandos ou módulos de SIG, que atenda à abordagem e às perguntas relacionadas, evitando-se desta forma, as inúmeras ações de tentativa e erro.

Recomendamos que o iniciante em análise espacial reserve ao trabalho realizado frente à tela do SIG-software, no máximo $30 \%$ do tempo destinado ao desenvolvimento de sua pesquisa. O tempo restante, a ser consumido preferencialmente no início da pesquisa, deveria ser dedicado ao SIG-mental. O SIG-mental é composto pelas etapas de contextualização da pesquisa em relação à matriz geográfica, formulação das perguntas geoespaciais a ela pertinentes e desenho de um fluxograma conectando os comandos do SIG-software a ser utilizado.

As perguntas aqui apresentadas constituem-se em sugestões didáticas iniciais, que não extinguem novos voos geoespaciais, mas poderiam ser tomadas como sementes para a formulação de outras perguntas, adaptadas a diferentes categorias de conhecimento geográfico e aos mais diversos SIG utilizados atualmente.

Acreditamos que este modelo possa auxiliar o pesquisador iniciante em geoprocessamento, no planejamento das principais etapas de análise espacial que serão posteriormente 
processadas no SIG. Não é demasiado lembrar aqui três comentários que sempre faço a alunos novos no geoprocessamento: os computadores foram construídos por pessoas que não os tinham em mãos; a geografia já existia antes do SIG, e o SIG não nasceu do próprio SIG.

\section{REFERÊNCIAS BIBLIOGRÁFICAS}

Berry, B.J. - Approaches to regional analysis: a synthesis. Annals of American Association of Geographers, 54(3):2-11, 1964.

Coffey, W.J. - Geography: towards a general spatial systems approach. London, Methuen, 1981.

Christofolleti, A. - As características da nova Geografia. Geografia, 1 (1):3-34, 1976.

Dolfuss, O. - A análise geográfica. São Paulo, Difel, 1973.

Eastman, R. - Idrisi version Andes. Clark Labs, Worcester, USA, 2010.

Ferreira, M.C. - Considerações teórico-metodológicas sobre as origens e a inserção do sistema de informação geográfica na geografia. In: A. C. Vitte (Ed.) - Contribuições à história e à epistemologia da geografia. Rio de Janeiro, Bertrand Brasil, p. 101-125, 2006.

Haggett, P. - Locational analysis in human geography. London, Edward Arnold, 1965.

Hepple, L.W. - The impact of stochastic process theory upon spatial analysis in human geography. Progress in Geography, 6:89-142, 1974.

Sack, R. D. - A concept of physical space in Geography. Geographical Analysis, 5(1):16-34, 1973.

Sack, R. D. - Chorology and spatial analysis. Annals of American Association of Geographers, 64(3):439-452, 1974

Virilio, P. - O espaço crítico. São Paulo, Editora 34, 1993. 
Artigo recebido em 23/07/2013.

Artigo aceito em 31/10/2013. 